\title{
A INFLUÊNCIA DO PCB NA CONSTRUÇÃo DO ENSINO PÚBLICO PRIMÁRIO DE BELÉM DO PARÁ DE 1945 a 1964
}

\author{
Maria José Aviz do Rosário \\ Universidade Federal do Pará (UFPA) \\ Professora do ICED-UFPA \\ mrosario@ufpa.br
}

\section{RESUMO}

Este texto discute e analisa a construção do ensino público primário de Belém do Pará, a partir das relações existentes entre os poderes políticos instituídos e os movimentos sociais organizadosliderados pelo Partido Comunista do Brasil - PCB,no período entre 1945 e 1964.A análise toma por base, centralmente, a expansão de escolas e a institucionalização dos órgãos oficiais do ensino. As fontes usadas para construção do texto compõem-se de mensagens governamentais, dos relatórios produzidos pelo poder político municipal e de depoimentos de comunistas históricos.Em sua conclusão, aponta-se que o PCB não mediu esforços para que o poder político instituído cumprisse com seu dever constitucional de oferta do ensino e que parte das demandas sociais educacionais asseguradas institucionalmente, foi articulada pelos movimentos sociais organizados sob a liderança do partido; que os prefeitos se esforçaram para demonstrar empenho na aplicação das leis aprovadas que criavam novas escolas e permitiam a expansão dos estabelecimentos de ensino, visando à garantia do atendimento ao ensino público primário municipal, bem como dos órgãos responsáveis pela sua coordenação. Desse modoé possível afirmar que o PCB, de 1945-1964, de fato, exerceu um papel importante na história da construção do ensino público primário de Belém do Pará. A movimentação se deu a partir de orientações nacionais e da produção articulada, discutida e elaborada pelos comunistas paraenses, que se configurou em um projeto de educação. Tal projeto foi discutido com a sociedade belenense e serviu de base a criação de escolas e órgãos oficiais de ensino municipal - Diretoria de Ensino, em 1949e o Departamento de Ensino Municipal, em 1958.

Palavras-chave: $\mathrm{PCB}$, ensino público primário, poder político

\section{THE INFLUENCE OF PCBS IN THE CONSTRUCTION OF PUBLIC EDUCATION PRIMARY OF BELÉM OF PARÁ BETWEEN 1945 AND 1964.}

\author{
Maria José Aviz do Rosário \\ Teacher's ICED-UFPA \\ mrosario@ufpa.br
}

This paper discusses and analyzes the construction of teaching primary audience of Belem do Para, from the relations between the powers established political and social movement organizations led by the Communist Party of Brazil - PCBs in the period between 1945 and 1964. The analysis is based, centrally, the expansion and institutionalization of school officials in school. The sources used for construction of the text messages are composed of government, the reports produced by the power of local political and personal statements of historical communities. In his conclusion, it is noted that the PCB did not measure efforts to set up political power to fulfill its constitutional duty of providing the educational and social demands that part of the education provided institutionally, was articulated by social movements organized under the leadership of the party; that the mayors have struggled to demonstrate commitment to the implementation of laws passed that created new schools and allowed the expansion of schools, aimed at ensuring compliance with the municipal primary public education, as well as the bodies responsible for coordination. Thus we can say that the PCBs, 1945-1964, in fact, played an important role in the history 
of public education of Belém do Pará Primary Drive took guidance from national production and articulated, discussed andPara drafted by the Communists, which was set up in an education project. This project was discussed with the community of Belém and served as the basis for establishment of schools and local school official bodies - Board of Education in 1949 and the Municipal Department of Education in 1958.

Keywords: PCBs,the primarypublic education, political power

Belém do Pará de 1945 a 1964, construiu sua trajetória educacional a partir de suas próprias necessidades mediadas pelo contexto de (re)democratização paraense e nacional, alicerçado pelos movimentos sociais organizados, com destaque para o Partido Comunista do Brasil - PCB, notadamente no que diz respeito à formação de opinião político-social-educacional paraense.

Este texto ${ }^{1}$ discute e analisa a construção do ensino público primário a partir das relações existentes entre os poderes políticos instituídos e os movimentos sociais organizados liderados pelo PCB no período da (re)democratização, 1945-1964. Análise recairá centralmente na expansão das escolas e na institucionalização dos órgãos oficiais do ensino público primário de 1945 a 1964, a partir das mensagens governamentais, dos relatórios produzidos pelo poder político municipal, dos depoimentos de comunistas históricos e outros dados de um contexto de franco processo democrático.

A participação do PCB nesse processo será analisada a partir de dois momentos distintos: do pós - Estado Novo até a cassação do Partido em 1948, e desta até 1962.

No primeiro momento, o PCB movimentou-se articulando suas propostas educacionais por meio dos Comitês Democráticos e Populares - CDP, em cuja base se identifica elementos de um projeto de educação. No segundo momento, o partido, ao se (re)articular, se voltou à mobilização e conscientização da sociedade belenense a fim de discutir a importância dos direitos sociais, entres eles os educacionais. Ressalta-se que tanto na legalidade quanto na clandestinidade, o PCB não mediu esforços para que o poder político instituído cumprisse com seu dever constitucional de oferta do ensino. O empenho do partido não foi em vão, porque parte das demandas sociais asseguradas institucionalmente, no período, foi articulada pelos movimentos sociais organizados sob sua liderança.

Em relação ao ensino, nesse período, observa-se que os prefeitos se esforçaram para demonstrar empenho na aplicação das leis aprovadas que criaram novas escolas e permitiram a expansão dos estabelecimentos de ensino, visando à garantia do atendimento ao ensino público primário municipal, bem como dos órgãos responsáveis pela sua coordenação.

A preocupação com o ensino público municipal estava ligada aos encaminhamentos políticos federal ou estadual, haja vista as conexões entre eles e os limites e alcance de cada esfera política. Em 1954, o governo estadual, ao se pronunciar publicamente anuncia essa perspectiva.

Quando assumimos o governo do Estado, constatamos que as escolas e os grupos eram insuficientes para o atendimento de todos que procuravam nossas casas de ensino. E, para contornar, em parte, essa premente necessidade, plenamente justificada com o aumento da população escolar, mandamos construir (3) grupos escolares na capital e recuperar outro 
edifício. (...). Estão projetadas as construções de mais dois grupos escolares, na capital, sendo um no bairro da Matinha e outro na Sacramenta, para melhor servir as populações escolares dos subúrbios (...) (ESTADO DO PARÁ, 1954, p. 64-65. Grifo nosso).

Ressalta-se que esse foi um período importante para o PCB e movimentos sociais que ao perceberem a disposição dos poderes políticos constituídos em fazer valer algumas de suas reivindicações, procuravam meios de (re)articulação e (re)organização. Sobre esse processo, Oliveira (2006) $)^{2}$, avalia a sua intensidade.

[...] Essas teses eu vivi muito porque foi exatamente na época em que entrei para o partido, se debatia muito as reformas que a sociedade precisava, onde entrava também a reforma do ensino, sobretudo a discussão em cima da educação, a Lei de Diretrizes e Bases do Anísio Teixeira. Então, nessa época você discutia muito as reformas de bases que a sociedade precisava e tirava encaminhamentos para encaminha-las.

Essa fala revela a preocupação do PCB para com o debate sobre a educação em nível nacional e como as questões em torno dela eram encaradas pelo partido em Belém.

Em relação ao poder político, a exegese às mensagens, demonstram que esse poder tinha preocupação com o atendimento desse nível de ensino, ao mesmo tempo em que lutava para apresentar um quadro que representasse a ampliação do número de escolas municipais.

A esse respeito, é interessante a afirmação do prefeito Major Luiz Geolás de Moura Carvalho, no início dos anos de 1950.

Assumindo as funções inerentes ao cargo de Chefe do Município de Belém, com o qual me distinguiu o Exmo. Sr. Major Luiz Geolás de Moura Carvalho (...) compreendi que a administração municipal precisava de um novo influxo de boa vontade e perseverantes esforços para a prossecução do seu interesse vital. (...) E assim tive que nortear o meu espírito por uma orientação segura, que me sugeriu a necessidade precípua de trabalhar ardorosamente, no objetivo de corresponder, indene de alardes e preconícios, à confiança que me foi depositada e, contemporaneamente, tornar-me merecedor da confiança de meus munícipes (PREFEITURA MUNICIPAL DE BELÉM, 1950, P. 7-8).

Nesse aspecto, a análise remete para as questões de disputas no interior da sociedade belenense que via florescer movimentos de várias tonalidades políticoideológicas. As disputas intencionavam a orientação em torno dos projetos que melhor representassem a sua linha de ação. Oliveira $(2006)^{3}$, alerta para o fato de que o PCB detinha hegemonia em segmentos formadores de opinião.

Depois, depois já na década de 50 e no início da década de 60 também é o PCB que faz a ligação entre a militância política e a militância cultural, aí, também tem um grande papel o PCB. Ele tinha hegemonia entre os intelectuais, entre os professores, entre os estudantes e utilizou muito 
disso fazendo com que a militância política encontrasse lugar com a militância cultural.

É nesse contexto, em meio às disputas, que o PCB pode contar com pessoas que historicamente estiveram muito próximas de sua linha de ação e com outras que foram sendo convencidas. Essas pessoas se filiaram, mobilizaram e lutaram em suas fileiras, algumas ligadas ao poder político instituído. A ligação do PCB, por intermédio dessas pessoas, foi importante, pois ajudou o partido a influenciar em algumas questões políticosociais. Essa ligação pode ser analisada a partir do que afirma Rui Barata ${ }^{4}$ a respeito de sua ligação com o governador Zacarias de Assunção.

Eu e o Zacarias de Assunção nos tornamos grandes amigos, apesar da diferença de idade. Isso porque, em 47, fui um dos que mais lutaram por sua candidatura a governador, dentro do Partido Social Progressista. Aparei todo tipo de aresta e, afinal teve o apoio da nossa legenda. Infelizmente, nessa eleição, a UDN resolveu lançar um candidato próprio, o Dr. Prisco Viana, dividindo a oposição ao baratismo-Moura Carvalho se elegeu tranqüilamente. Já em 50, a união contra Barata foi possível, com a reunião de todos os partidos oposicionistas, no que se chamou Coligação Democrática Paraense. Assunção obteve uma vitória memorável, embora apertada. Eleito governador nunca deixou de me distinguir, tanto que, ao amanhecer, muitas vezes ia tomar café em minha casa e conversar sobre os rumos da política local. Elaborei muito de seus discursos e pronunciamentos.

Nessa conjuntura, outro aspecto importante que permeava as falas dos prefeitos diz respeito às questões que envolviam a construção desse processo democrático, pois os referidos prefeitos, na qualidade de representantes do poder político constituído, ou seja, do estado, sabiam que é no município que o Estado adquire a sua clara feição e engendra sua força motriz, sendo mediador, ator e principal articulador das tramas nas quais a sociedade se envolve. Portanto, sabiam também que é durante os processos de construção da democracia que as relações sociais se aprofundam, provocando uma reorientação na condução do processo político conduzido pelo estado.

Entendiam os prefeitos que o município, por representar o poder político (executivo) instituído, era o principal mediador, elaborador e efetivador das propostas educacionais públicas nas escolas públicas belenenses, com todas as implicações político histórico - sociais que o momento histórico apresentava.

Nesse sentido, o poder político municipal é incisivo ao discutir a sua preocupação com as garantias sociais. A particularidade é revelada no diálogo com a CMB.

Neste empenho sou o primeiro a reconhecer que se impõe a colaboração amistosa e patriótica de todos vós, Senhores Vereadores, para com o Executivo Municipal. Tão cônscio desse escopo estou que, se o relato que ora faço não fosse decorrente de uma imposição legal, fá-lo-ia espontaneamente a fim de que a essa douta Câmara chegasse o conhecimento da eclosão de empenhos e medidas, determinações e providências úteis com que tenho precedido em minha administração para com as garantias sociais (PREFEITURA MUNICIPAL DE BELÉM, 1950, P 8-9). 
Seguindo essa linha de raciocínio, observa-se que há um propósito de alcance da ordem institucional circunscrita e a representação dos belenenses na Câmara Municipal de Belém - CMB.

Em 1950, o poder político usava como argumento o processo democrático em curso: "com o retorno do País à ordem constitucional pela promulgação da Carta Magna de 18 de setembro de 1946" (PMB. 1950 p. 7). E quando faz referência à Instrução Pública Municipal anuncia que, “(...) a Prefeitura de Belém, vencendo todos os óbices e sacrifícios, pôs em funcionamento várias escolas municipais" (PMB. 1950, p. 65)

Em relação ao processo democrático, houve uma abertura maior do diálogo com os comunistas do PCB. Segundo Oliveira $(2006)^{5}$, durante o governo de Juscelino Kubitschek.

[...] Então em 55 o governo Juscelino e o Barata também já estavam com outra visão em relação ao PCB. Barata era populista em determinada fase o populismo de dele foi bastante progressista e ele foi absolutamente revolucionário, antes de 30 e também em 30. Então em 55 com o Barata no governo e o Juscelino na Presidência da República a gente pode se preocupar em construir uma linha política de abertura democrática de construção de aliança popular.

O Juscelino era realmente um cara democrata. Então aqui no Pará a gente pode lutar, fazer as campanhas pela educação, discutir propostas, para professores, etc.nesse período de Juscelino, [...] isso foi facilitado porque o governo de Juscelino ofereceu uma abertura democrática.

Entretanto, é preciso atentar para o fato de que só este aspecto não assegura a implantação da democracia, porque a democracia é a mais completa forma política a imperar, pois permite que a maioria participe das tomadas de decisão no campo políticopragmático.

Portanto, a construção do processo democrático requer compreender a democracia como estratégia para alcance de uma finalidade, ou seja, ela deve ser construída continuadamente. E ainda que o governo garantisse tal abertura, os conflitos que se originavam nas classes sociais, continuavam e, se o contexto não sofreu significativa alteração político-social, o discurso democrático não era central e, desse modo, configurava como um discurso vazio, oco e sem substância capaz de convencer o conjunto da sociedade belenense para a sua validade.

A expansão, visando ao atendimento da instrução pública, ampliou o número de escolas, porém sem nenhuma referência à Diretoria de Ensino Municipal, órgão oficial de ensino, no período.

Sete novas escolas foram inauguradas, todas bem instaladas e já em pleno funcionamento: "Diva Assunpção", "Osvaldo de Caldas Brito", Ezeriel Mônico de Matos"; "República do Peru", República do Uruguai", "República da Bolívia", e "República de Portugal (PREFEITURA MUNICIPAL DE BELÉM, 1950, P. 27).

Essa perspectiva demonstra que, apesar da instituição do órgão oficial de ensino, em 1949, o poder político preocupava-se com a criação de escolas porque essas 
instituições davam maior visibilidade ao estado e atenuavam os conflitos sociais, até porque em boa medida a população belenense queria ver garantido o acesso ao ensino como um dos seus direitos constitucionais, independentemente do órgão que o coordenava. Isso pode ser depreendido da fala de Oliveira $(2006)^{6}$

[...] o PCB já estava na rua com campanha dos estudantes pela meia passagem nos bondes, nos ônibus, no cinema... Tanto que para as pessoas, isso era considerado uma questão subversiva, imagina, olha se quando eu era estudante de medicina, eu fui estudante de medicina de 1955 a 1960, nesse período ainda era subversivo você dizer que a saúde era um dever do Estado e um direito do cidadão, isso era considerado um ato subversivo e de comunistas, de socialização da medicina, isso já bem cá. Tu imaginas o que era naquela época o cara dizer que o povo tinha direito à educação.

Em relação à organização do ensino, no que diz respeito ao número de escolas, a observação é a de que a rede escolar era insuficiente para atender as necessidades. Nesse sentido, o poder político municipal por ser o responsável pela efetivação do ensino como um direito dos belenenses, continuava a cumprir o seu programa político-educacional, ainda que reconhecesse as limitações do erário público para essa empreitada.

Temos a satisfação de informar que, no ano letivo de 1952, funcionaram 23 escolas, sendo 11 municipais e 12 subvencionadas. [...] Além do curso primário ministrado em turmas matutino e vespertino, funcionaram ainda três escolas supletivas, para alfabetização de adultos, sendo duas nesta cidade e uma no lugar "ponta Grossa", em Icoaraci. [...] No ano passado, duas escolas foram inauguradas: a "República do Chile" e a "Estados Unidos", em homenagem as duas repúblicas irmãs (PREFEITURA MUNICIPAL DE BELÉM, 1953, p. 113).

A Diretoria de Ensino Municipal, na qualidade de órgão que coordenava as ações políticas, pedagógicas e práticas relativas ao ensino, inseriu uma diretriz interessante tomada no âmbito da organização do ensino público primário municipal, a qual revela a preocupação para com a formação dos estudantes belenenses.

A Diretoria de Ensino, no ensejo que as datas nacionais oferecem, difunde a educação moral e cívica, tão necessária à formação da nossa infância, organizando festas em que são participantes os próprios estudantes (PREFEITURA MUNICIPAL DE BELÉM, 1953, p. 113).

Considerando que a Diretoria de Ensino foi criada por lei da CMB, em 1949, e que só agora aparece nas falas oficiais, há de se inferir que a preocupação do poder político municipal centrava-se no aumento de escolas e em segundo plano no órgão que possibilitava a organização de fato e de direito do ensino a cargo do poder político municipal. Ainda assim, é possível observar a preocupação do órgão oficial em relação à dimensão que privilegiava as regras de conduta, como é o caso da instituição da disciplina Educação Moral e Cívica ${ }^{7}$. 
Por outro lado, pode-se inferir que a implementação da disciplina Educação Moral e Cívica nas escolas públicas municipais era em decorrência do poder político instituído costurar uma contraposição às orientações dos movimentos sociais organizados de esquerda ligados ao PCB, pois, como já foi ressaltado, o partido encontrava-se na ilegalidade, mas como não foi desarticulado, trabalhava no sentido de orientar politicamente ações que garantissem os direitos sociais, entre eles, os educacionais a partir de outra perspectiva, que, na visão de Araújo (2006) ${ }^{8}$, seria "uma militância geral pautada nas metas do partido no sentido da conquista de um mundo socialista como um processo".

Voltando-se à questão das escolas, observa-se que o poder político ao centrar a preocupação no aumento de escolas, visando assegurar o ensino público primário, definido como instrução pública, usava como argumento o fato de compreender a escola como uma instituição sob sua responsabilidade e que nela seriam resolvidos os problemas do ensino.

Compreendendo o Executivo Municipal a imperiosa necessidade de difundir e ampliar cada vez mais a campanha da instrução pública como fator evidente, indiscutível e inadiável de progresso do povo e, conseqüientemente, da nacionalidade, não tem este poupado esforços para que, neste setor, tudo possa conseguir e realizar a favor de tão elevados ideais (PREFEITURA MUNICIPAL DE BELÉM, 1953, p. 56).

Analisando essa perspectiva, infere-se, o discurso que coloca a escola como mola propulsora de desenvolvimento e progresso de um povo por si só não se sustenta, porque estes dependem de um conjunto de fatores, entre os quais o acesso ao ensino como uma conquista social, em lugares próprios, as escolas, entendidas como instituições que contribuem para o desenvolvimento e o progresso social.

Por volta de 1956, o poder político instituído ao discutir as questões de interesse da sociedade belenense, faz alusão ao seu cargo, lembrando que esse foi outorgado pelo povo de Belém do Pará, "[...] antes do término do exercício corrente veremos encerrado o mandato que o povo nos conferiu e estaremos prontos a transmitir a espinhosa missão que nos foi confiada ao nosso sucessor" (PMB, 1957, p. 1).

Sabia a administração que estava impregnada de legitimidade, conferida pela sociedade de Belém, por intermédio do voto, o que se configura como de importância ímpar, uma vez que o voto é um dos elementos constituintes do processo democrático.

Esse é um elemento importante de análise porque a discussão no contexto da sociedade belenense passava pela (re)articulação dos movimentos sociais, como o PCB. Pereira (2006) $)^{9}$ ao se manifestar sobre a organização dos trabalhadores ligados ao partido, informa que:

Então, em 56 trabalhando na Petrobrás com um punhado de bravos companheiros nós empenhamos para fundarmos o sindicato do petróleo e é aí que eu tive mais participação política, porque até então, era sem nenhuma vinculação ao partido, sem nenhuma expressão que pudesse, de fato, como pertencente ou representasse o partido ou coisa e tal.

A análise demonstra que a escolha dos prefeitos ia ao encontro da idéia de controle social que destoava do controle baseado apenas na perspectiva de uma base política de determinado grupo, quer dominante ou não. 
Ao se referir à educação, o prefeito enfatiza a expansão de escolas. "No setor de educação, continuamos a construir escolas que este ano proporcionam alfabetização a mais de seis mil crianças" (PMB, 1957, p. 3).

E desse modo, destacava o ensino como um dos setores a merecer atenção especial. "O ensino primário gratuito, um dos encargos atribuídos pela Constituição Federal vigente aos municípios, concorrentemente com os estados, foi outro setor que mereceu preocupação deste Executivo" (PMB, 1957, p. 19).

Em 1956, funcionaram com regularidade quinze escolas municipais, onde foram matriculados 4.638 alunos, além dos cursos noturnos ministrados nas escolas "República dos Estados Unidos", "Dr. Alcindo Cacela", "República da Bolívia", e Dr. Amazonas de Figueiredo." Além das escolas em funcionamento, este Executivo conseguiu iniciar a construção de mais 3 outras, as primeiras de uma série de sete, as quais situam-se na Vila de Mosqueiro e nos bairros da Matinha e Condor, tendo já as duas últimas citadas sido inauguradas no início do ano letivo corrente (PREFEITURA MUNICIPAL DE BELÉM, 1957, p. 19-20).

Em 1952, a conquista da autonomia, com eleições para prefeito, porém no campo educacional, continuava a se espelhar nas diretrizes traçadas no plano estadual, tendo como referência a Secretaria de Educação e Cultura - SEDUC, ou seja, a autonomia conquistada pelo voto não fez com que as instituições sociais se tornassem igualmente autônomas para coordenar suas demandas específicas.

Em 1958, o prefeito delineou sua "concepção" de governar articulada à preocupação com o povo que o elegeu.

\begin{abstract}
Ressaltamos, desde logo, o nosso permanente desejo de trabalhar de portas abertas, governando em contacto direto com o povo que nos elegeu, esse povo que merece dias melhores e que, para obtê-los, vai às ruas e às urnas manifestar o seu repúdio aos que através de arbitrariedades e abuso do poder, gerados pela defesa de interesses pessoais e mesquinhos, somente trazem a infelicidade a esta terra. Administrando sempre às claras, fazemos questão que o povo esteja permanente bem informado sobre os negócios municipais, conforme a nossa consciência e o nosso espírito democrático, para que todos, no uso pleno do direito inalienável que lhe assiste, possam saber o que estamos fazendo, o modo como estamos agindo, a honestidade e vontade de acertar com que pautamos nossos atos administrativos (PREFEITURA MUNICIPAL DE BELÉM, 1958, p. 1-2. Grifo nosso).
\end{abstract}

Ressalta-se que Belém do Pará vivia em um contexto dos mais interessantes do ponto de vista político. O poder político constituído e ungido pelo voto, portanto "porta voz" oficial do povo; e o PCB, às voltas com suas ambições e discussões partidárias em torno da conquista do poder, movimentavam-se em direção à sociedade belenense com objetivos claros de infuenciá-la. Sobre a movimentação do partido, Oliveira $(2006)^{10}$ afirma,

Quando a gente, aqui, em 57, falava em apoiar, por exemplo, Aurélio do Carmo esse pessoal ficava horrorizado. Não era porque a gente achasse que o Aurélio do Carmo era uma figura ideal, claro que não, mas era um 
fato que tinha, digamos um papel a cumprir em relação à burguesia nacional. Foi o cara que contra a pressão do imperialismo norte americano fez uma fábrica de cimento lá em Capanema com aparelhagem vindo da Tchecoslováquia, de um país socialista, isso intermediado pelo Partido Comunista. Eles não aceitavam isso, eles não acreditavam no caminho pacífico da Revolução. Isso aí, eu até acho, que dependendo de como você colocar, eles tinham razão em algumas coisas, não razão total e completa. Eu acho que realmente essa coisa da gente achar que a Revolução pode ter um caminho democrático, até hoje, esse caminho democrático não surgiu em nenhuma parte do mundo.

Quanto à expansão e ampliação das escolas municipais, o poder político instituído articulava projetos municipais com as instituições federais, revelando, com isso, as conexões existentes entre os poderes federal, estadual e municipal.

Simultaneamente com as providências visando à construção de novas escolas nos diferentes pontos do município, em convênio com o Instituto Nacional de Estudos Pedagógicos, bem como a ampliação das já existentes, para possibilitar a elevação da matrícula, estamos trabalhando incansavelmente para fazer funcionar o Ginásio Municipal (PREFEITURA MUNICIPAL DE BELÉM, 1958, p. 9).

É a partir de 1958, com a criação do Departamento Municipal de Educação e Cultura, que o ensino público primário em Belém do Pará começa de fato e de direito a trabalhar na perspectiva de uma organização própria. Essa assertiva é decorrente da análise sobre o funcionamento das escolas existentes a partir da Diretoria de Ensino Municipal.

Diretoria de Ensino Municipal - Escolas Municipais. No que se refere ao Ensino Municipal, assim podemos sintetizar as suas atividades, no exercício passado: funcionaram, em 1957, dezessete escolas municipais, tendo sido matriculados 4.628 alunos. Comparativamente ao ano anterior, funcionaram, nesse exercício, mais três escolas, que foram a "República da Venezuela", "República da Espanha" e "República do Paraguay" (PREFEITURA MUNICIPAL DE BELÉM, 1958, p. 21).

Essa perspectiva demonstra que o arcabouço da organização do ensino público primário, considerando o aumento do número de escolas e a coordenação do ensino pelo órgão oficial, apresenta-se de forma mais delineada e, desse modo, assume importante característica de elemento constitutivo de organização do ensino público primário do Município de Belém.

A mudança representa indícios de que o poder político antenado com as discussões político-educacionais procurava articular um posicionamento mais organizativo para garantia do ensino público primário e ao mesmo tempo firmar o seu discurso de governar com o povo e pelo povo, no sentido do atendimento de suas reivindicações.

E não ficamos apenas esperando que as reivindicações populares viessem até nós. Fomos ao encontro delas, visitando diariamente os subúrbios e realizando semanalmente audiências públicas nos bairros mais longínquos de nossa cidade, para proporcionar às populações menos 
favorecidas e mais sacrificadas, quando não a satisfação material de suas necessidade, por faltar maiores recursos ao erário municipal, pelos menos o lenitivo de dar-lhes a conhecer que os homens de governo ainda sentem as aspirações e os anseios do povo, ainda conhecem os seus problemas, ainda procuram soluciona-los e não se quedam inativos, após a conquista dos mandatos de que estão investidos (PREFEITURA MUNICIPAL DE BELÉM, 1959, p. 2).

Na verdade, o discurso sobre o regime democrático era parte importante da pauta dos prefeitos na afirmação da importância como um dos principais componentes de promoção da esperança do povo belenense e manutenção dos alicerces das instituições sociais.

Assim, estimulando e fazendo renascer esperanças latentes ou já extintas, pensamos contribuir para o fortalecimento do regime democrático em que vivemos, porque entendemos ser a desesperança o fator primordial da revolta que mina as consciências, levando o povo a gestos extremos, que abalam os alicerces das instituições sociais (PREFEITURA MUNICIPAL DE BELÉM, 1959, p. 2).

Entretanto, ainda que os discursos apontem nessa direção, é preciso não esquecer que a linha divisória da relação entre estado, poder político instituído e busca pela construção democrática é muito tênue, já que uma dimensão faz parte da outra e irradiamse entre si manifestando-se no campo histórico, político e social. A atuação do poder político dá-se por intermédio de um conjunto de fatores existentes nos espaços nos quais se encontra instituído.

Esse entendimento supõe que todos os elementos utilizados para forjar a mediação entre estado, poder político constituído e a construção da democracia requer participação social e política dos grupos organizados e da sociedade de modo geral. Sabese, pois, que existem inúmeras vias, por intermédio das quais os grupos ou os indivíduos podem constantemente participar do processo político-social do estado. Este, para se manter institucionalmente equilibrado, precisa atender parte das demandas do conjunto de classes, organizado ou não no interior da sociedade.

Voltando-se à questão do discurso sobre o regime democrático, como parte importante da pauta dos prefeitos, é preciso sublinhar que a análise sobre representatividade compreende que não basta pensar só na possibilidade de fortalecer o regime democrático, mas, sobretudo, pensar no caminho trilhado por aqueles que estão no poder, na qualidade de representantes. Bobbio (1998, p 34. Grifo nosso), ao analisar essa questão da representação, afirma:

De resto, a democracia representativa também nasceu da convicção de que os representantes eleitos pelos cidadãos estariam em condições de avaliar quais seriam os interesses gerais melhor do que os próprios cidadãos, fechados demais na contemplação de seus próprios interesses particulares; portanto, a democracia indireta seria mais adequada precisamente para o alcance dos fins a que fora predisposta a soberania popular. 
Como no Brasil a democracia é representativa, ou seja, elege-se representes que, em nome do povo, governam e elaboram as leis do país, o poder político municipal não poderia passar ao largo de tal questão, ao contrário, (re)arfimava sua crença nessa posição e a partir disso construía elementos que lhe possibilitavam a manutenção do poder político.

Segundo essa linha de raciocínio, ao tratar do setor referente à educação escolar, o prefeito usa o argumento de que a educação é fundamental para a formação democrática e elevação cultural do povo e que, por isso, trabalhou de forma objetiva para a consecução dos êxitos esperados (cf. PMB, 1959).

Quando faz referência ao aumento de escolas municipais, assinala que é motivo de orgulho para sua administração, porque corrobora seus objetivos de administrador representante do povo.

\begin{abstract}
Além das dezoito escolas primárias que encontramos ao início de nossa gestão, tivemos a felicidade de inaugurar e colocar em funcionamento, em apenas um ano de governo, mais cinco outras, realizando, em menos de doze meses, perto de trinta por cento do que todos os governos anteriores reunidos fizeram, neste setor. Estas novas cinco escolas primárias do Município têm denominação e localização seguinte: Escola "Padre Teodoro Kocke", em Tenoné; Escola "República do Panamá" em São Braz"; Escola Prof. "Antonio Gonçalves da Rocha", no Jurunas; Escola "Dr. Liberato de Castro"; na Cremação e Escola "Prof. Remígio Fernandez", na Pedreira (PREFEITURA MUNICIPAL DE BELÉM, 1959 , p. 48).
\end{abstract}

Analisando o crescimento do número de escolas, infere-se que a organização do ensino a cargo do poder público municipal ganhava contorno de uma instituição de grande importância no contexto da educação paraense. $O$ crescimento do número de escolas foi significativo o que significa dizer que do ponto de vista quantitativo era possível observar efetivação do ensino de fato e de direito.

Neste setor, cremos ter realizado muito mais do que esperávamos. Graças ao êxito que coroou os nossos esforços, hoje o Município de Belém conta com quarenta e quatro unidades escolares, incluindo entre Grupos Escolares, Escolas Reunidas, Escolas Isoladas, Escolas Supletivas, Curso de Admissão, Escolas Reconhecidas e o Ginásio Municipal (PREFEITURA MUNICIPAL DE BELÉM, 1959, p. 48-49).

A análise dos dados demonstra que a organização do ensino público primário, considerando a expansão e o órgão oficial de ensino, estava de fato e de direito instituída, pois, ao mesmo tempo em que elas destacam o crescimento dos estabelecimentos escolares como marca de expansão, enumeram esses feitos como uma das responsabilidades do órgão oficial de ensino do Município de Belém.

Neste setor, pois, um dos desenvolvidos pelo Departamento Municipal de Educação e Cultura, nossas preocupações voltaram-se especialmente para a criação e conservação de escolas e para instituição de novas unidades escolares, ao mesmo tempo em que asseguramos o funcionamento regular das unidades já existentes (PREFEITURA MUNICIPAL DE BELÉM, 1959, p. 50). 
Nesse final da década de 1950, o poder político municipal procurava apresentar um quadro favorável para o campo da educação, o qual denominava Educação e Cultura.

O quadro de criação de escolas era o seguinte: 3 grupos escolares e mais 2 projetados; 19 escolas municipais para o ensino primário e mais 3 em construção (PMB, 1960, p 11).

O quadro apresentado ia ao encontro do argumento de que a educação é fundamental para a formação e elevação cultural do povo. Nesse sentido, listava o crescimento do número de escolas, o que se configurava na expansão do ensino, a criação dos órgãos oficiais de ensino (Diretoria de Ensino Municipal ou pelo Departamento Municipal de Educação e Cultura), bem como procurava mostrar outros feitos educacionais realizados no âmbito do ensino de Belém do Pará. Entre os feitos, listava os cursos supletivos que foram oferecidos para dar oportunidades aos jovens e adultos privados de instrução elementar; ao ensino secundário, ministrado no ginásio municipal Dr. Alfredo Chaves; à educação extra-escolar; ao serviço social; à distribuição de merenda escolar; ao serviço de canto orfeônico; à educação física e bibliotecas escolares; à distribuição gratuita de livros didáticos; aos cursos de férias para professores, visando proporcionar treinamento especializado e atualização pedagógica para o corpo docente das escolas da PMB; e à implantação do Serviço de Orientação Pedagógica (cf. PMB, 1959).

Essas realizações de cunho organizativo e de coordenação contribuíram para dar visibilidade e fortalecimento às bases do ensino em Belém do Pará. O que se percebe, pela análise da década de 1950, é que o ensino público primário a cargo do município de Belém a cada ano se fortalecia como uma das instituições que materializavam idéias e aspirações sociais em Belém e que pela sua expressão foi adquirindo, no contexto histórico, político e social características próprias, chamando a atenção do poder político constituído.

Nesse particular, há concordância do PCB, por fazer parte da articulação com os movimentos sociais organizados, a exemplo daqueles sob a sua liderança. Oliveira (2006) ${ }^{11}$ avalia que houve avanços em termos de concepção de educação.

$\mathrm{Na}$ área da educação sobretudo na década de 50, no finalzinho da década de 40, mas sobretudo na década de 50 houve um avanço em termos de concepção da educação. Não que ela tivesse se espraiado para as escolas, mas houve um avanço, tanto com Malcher como com Barata e como os prefeitos eram indicados pelos governadores e interventores, eles eram indicados. Então eles seguiam a mesma cartilha. Então esse negócio pra dizer, ah! Eu tenho autonomia pra fazer a minha parte, não! Mas houve um grande avanço na questão da concepção.

A discussão que envolve a garantia da escola pública no Brasil é antiga. Anísio Teixeira (1994, p. 103), ao discuti-la tendo em vista o contexto local, aponta a criação de órgãos educacionais como elementos importantes desse processo.

O estado é que confiaria a órgãos locais, previstos na lei orgânica dos municípios ou numa lei orgânica de educação, a administração por motivos de expediente, pois o órgão local seria mais eficiente do que o órgão estadual, distante na gerência da escola; por motivos sociais, pois assim melhor se caracterizaria a natureza local da instituição e o seu 
enraizamento na cultura local; e ainda por motivos econômicos, pois isso permitiria a adaptação da escola aos níveis locais.

A análise que se faz dos anos de 1960 indica que o prefeito, ao discutir as suas responsabilidades no atendimento das demandas sociais, se deteve na avaliação do processo democrático e para isso se fundamentava em teorias que deram conta de analisar o papel dos governos nos regimes democráticos.

A organização do regime democrático, com a nítida separação dos Poderes, doutrina que encontrou em Montesquieu um ardente defensor e que serviu de base para o estabelecimento da nova ordem política erigida com a Revolução Francesa, não só delimita perfeitamente as atribuições das diversas esferas que formam a administração pública, como, e aí está o seu grande mérito, permite a fiscalização das atividades de um Poder pelo outro, a fim de evitar os abusos e prevaricações dos que são escolhidos pelo povo para defesa e gerência da coisa pública (PREFEITURA MUNICIPAL DE BELÉM, 1960, p. 1).

A idéia de que a organização do regime democrático prevê também a fiscalização de um poder pelo outro permitia que nas diversas atividades dos setores da administração municipal fosse ressaltada a colaboração da CMB para a resolução dos problemas relativos ao ensino.

É de justiça ressaltar que nesta verdadeira cruzada não tem faltado o apoio e a mais decidida colaboração dos ilustres membros dessa Egrégia Câmara, que sempre encararam o problema do ensino como um dos problemas mais sérios de nosso povo, preocupando-se em dar meios ao Executivo para, se não de solucioná-los, pelo menos enfrentá-lo com energia (PREFEITURA MUNICIPAL DE BELÉM, 1960, p. 1-2).

Em relação à educação, o poder político instituído faz um apanhado positivo das realizações empreendidas. Ao mesmo tempo, apresentava a idéia de que a escola, para o povo, significava a disseminação da cultura, usando como meio as escolas municipais.

A educação de nosso povo, com assistência efetiva à população escolar, tem recebido de nosso governo a mais carinhosa atenção. Em todos os recantos da cidade, nos mais distantes subúrbios, em lugares muitas vezes que se apresentam quase inacessíveis, temos levado a cultura, através da criação e aparelhamento de escolas municipais (PREFEITURA MUNICIPAL DE BELÉM, 1960, p. 9).

Ainda que o balanço sobre a educação municipal fosse positivo, há também o reconhecimento, por parte do poder político, da falta de escolas. Portanto, seria necessário fazer muito mais para avançar a fim de assegurar a todos o ensino público a cargo de Belém do Pará.

As escolas que existem em Belém ainda são insuficientes. Todos os anos, constatamos com tristeza que milhares de crianças ficam impossibilitadas 
de estudar, devido não obterem matrículas nas escolas públicas e não poderem arcar com as despesas, cada vez maiores, das escolas particulares (PREFEITURA MUNICIPAL DE BELÉM, 1960, p. 10).

Nessa ocasião, o Departamento Municipal de Educação e Cultura, na qualidade de órgão oficial do ensino municipal, assumia à coordenação dos serviços educacionais a cargo do poder político municipal, inclusive no relacionamento com o governo federal, para solucionar a problemática educacional no âmbito do município. Desse modo, era reafirmada a conexão com o poder político federal.

O Departamento Municipal de Educação e Cultura fiscaliza e orienta o ensino no município, programando as atividades letivas e resolvendo todos os assuntos relativos às nossas escolas, inclusive coordenando o seu trabalho com os demais órgãos especializados e procurando interessar o governo federal para a solução de nossas dificuldades (PREFEITURA MUNICIPAL DE BELÉM, 1960, p. 10).

A análise demonstra essa preocupação de se buscar soluções no governo federal e permite que se verifiquem as conexões existentes na época entre as esferas de poder e o alcance delas, ou seja, pelo teor da mensagem, o poder político municipal reconhecia seus limites para assegurar o ensino sob sua responsabilidade e ao mesmo tempo buscava arranjos institucionais, observando o respeito ao princípio democrático de tomada de decisão.

Quanto ao Departamento Municipal de Educação e Cultura, este, entendido como um elemento constituinte da organização do ensino de Belém, o poder político assumiu que essa instituição, responsável pela coordenação das atividades educacionais, contribuía para o engrandecimento e progresso da Cidade de Belém, revelando a importância de tal órgão para a condução do ensino público primário.

Foi de grandes e preciosas atividades em prol do engrandecimento e progresso de nossa cidade, e, conseqüentemente de nossa terra, o ano de 1959, no que se refere aos órgãos anexos ao Departamento Municipal de Educação e Cultura. Tendo em funcionamento seus dois grandes baluartes, como sejam, e a Divisão de Educação Escolar e divisão de Educação Extra-Escolar, o Departamento Municipal de Educação e Cultura fez encerrar o período de 1959 conseguindo vencer os entraves que o acaso se lhes apresentou, obstáculos que, todavia, não esmoreceram e nem empanaram os ideais de seus dirigentes (PREFEITURA MUNICIPAL DE BELÉM, 1960, p. 10).

No tocante às escolas municipais, é interessante observar a composição do quadro de escolas em funcionamento, considerando as Vilas de Mosqueiro e de Icoaraci, e o quanto era importante para o poder público municipal assegurar o ensino primário, de sua responsabilidade.

Funcionaram vinte e três escolas municipais com sede na capital; seis unidades escolares sediadas na Vila de Mosqueiro e duas na Vila de Icoaraci. Subvencionou a comuna, dezesseis unidades em Belém, três unidades escolares na Vila de Mosqueiro e duas unidades na Vila de Icoaraci. Para alfabetização de adultos, funcionaram onze cursos 
supletivos. Em suma, tivemos em Belém trinta e nove escolas; em Mosqueiro nove escolas e, em Icoaraci quatro escolas, num total de sessenta e três unidades escolares (contando com os 11 cursos supletivos) (PREFEITURA MUNICIPAL DE BELÉM, 1960, p. 11. Grifo nosso).

Quando a discussão nos anos de 1960 se pautou na relação do prefeito com a concepção político-partidária, observa-se uma continuidade nas diretrizes governamentais, ou seja, não foram processadas mudanças substanciais no seu conteúdo. Isso se explica, em parte, porque o comando político permaneceu ligado ao mesmo partido, PSD.

E mesmo quando ocorriam mudanças, o argumento usado ligava-se à idéia do debate democrático preconizada pelo poder político instituído, assegurar mais autonomia aos municípios e, em conseqüência, ao ensino. Essa perspectiva revela o grau de importância do ensino como um dos elementos de fortalecimento de uma determinada concepção.

A autonomia reivindicada para os municípios, no início dos anos de 1960, incidia em divisão de poder, segundo palavras do prefeito "fundamentadas" em teóricos que discutiam o assunto.

Situamo-nos entre os que reivindicam maior autonomia para os municípios. Vamos além, com o insigne constitucionalista Pontes de Miranda, para afirmar que qualquer programa político que não seja o de dar o máximo poder possível aos municípios, fazendo-os, com a União, as duas verdadeiras estruturas da vida constitucional do Brasil, pois são as únicas duas realidades criadoras de riqueza, de agregação e de energia, não tocará, sequer, o problema estrutural do Brasil (PREFEITURA MUNICIPAL DE BELÉM, 1960, p. 4).

O prefeito alegava que a autonomia existente em Belém do Pará era concedida pelos poderes políticos estadual e federal em doses homeopáticas, provocando relações desiguais e a não compreensão do município como cidade que se caracteriza pela fixação do homem ao solo. Essa perspectiva precisava ser mudada, pois, segundo o prefeito, a autonomia era "resultante da fonte constitucional, a autonomia municipal, nos dias que correm, é algo que não pode ser tido como mera delegação do Estado" (PMB, 1961, p. 4).

Ao se examinar essa questão, percebe-se a intenção de construção de um argumento democrático no qual a participação ampla na vida política institucional fosse considerada vital para o desenvolvimento social e político e que, no campo da educação, a promoção da democracia assumisse características de um processo comum a todos e não a uma parcela privilegiada.

Em relação à organização do ensino, o maior feito, no que diz respeito à expansão das escolas, foi a criação do ginásio municipal Alfredo Chaves, como uma contribuição ao ensino médio gratuito em Belém do Pará. Em se tratando do ensino primário, foco central do poder público, a expansão de escolas "à difusão do ensino primário, foi [...] enriquecido com a criação de mais uma unidade na Vila de Icoaraci, (...) e ainda uma outra em nossa capital, Escola Império do Japão, instalada em prédio próprio" (PMB, 1961, p. 42).

Considerando o atendimento do ensino primário e secundário e o fato de que a educação em todos os níveis era assegurada constitucionalmente como um direito 
de todos, inicialmente infere-se que era igualmente legítimo o ato de criação de escolas para auxiliar na efetivação do ensino secundário, em Belém do Pará. Entretanto, quando a análise recai sobre as fotografias das escolas citadas, Ginásio Alfredo Chaves e Império do Japão, não se pode deixar de perceber as diferenças entre um prédio e outro.

As mudanças operadas, nos anos de 1960, na organização do ensino, a partir do processo de expansão das escolas municipais e da transformação do órgão oficial de educação, a Diretoria de Ensino Municipal, em Departamento de Educação e Cultura, com "status" de Secretaria, fortaleciam a organização do ensino público primário com vistas à efetivação do ensino como um direito de todos e dever do estado.

Amplia-se, deste modo, o número de unidades escolares mantidas pela Prefeitura, o que motivou a transformação da antiga diretoria de Ensino Municipal em Departamento de Educação e Cultura, com maior campo de atuação (PREFEITURA MUNICIPAL DE BELÉM, 1961, p. 42).

Em relação à expansão de escolas, o poder político municipal apresentava trinta e duas unidades escolares em funcionamento com níveis de cursos elementar e complementar.

Departamento de Educação e Cultura. As atividades deste setor se concentram na atuação do Departamento Municipal de Educação e Cultura, este por sua vez, através de três diretorias: a Geral, a de Educação Escolar e a de Educação Extra-Escolar. No ano findo, funcionaram trinta $\mathrm{e}$ duas unidades escolares (PREFEITURA MUNICIPAL DE BELÉM, 1961, p. 42).

Em $1962^{12}$, o poder político apresentava um cenário desanimador no que diz respeito à administração do município, "quase toda a máquina administrativa estava desorganizada, desaparelhada e desprovida de meios para seu funcionamento" (PMB, 1962, p. 4).

Entretanto, ao mesmo tempo em que o poder político apresentava um quadro desfavorável, conclamava a colaboração da $\mathrm{CMB}$, pois acreditava na possibilidade da realização de um trabalho conjunto com o qual fosse revertido o quadro "sombrio e até certo ponto nebuloso de um período que desejamos ver prontamente superado", (PREFEITURA MUNICIPAL DE BELÉM, 1962, p. 5) em que se encontrava o setor administrativo-político de Belém do Pará.

São números de estarrecer, reconhecemos e lamentamos levar a Vv. Excias estes tristes elementos, o que fazemos em honra da verdade, e para justificar o retardo da execução do programa de trabalho que, mercê de Deus, pretendemos realizar neste Município e para o qual, no momento oportuno, esperamos merecer o honroso e necessário apoio dessa Egrégia Câmara (PREFEITURA MUNICIPAL DE BELÉM, 1962, p. 5).

Desse quadro quase que "caótico", pode-se inferir que a fala do prefeito é um reflexo do contexto político-social bastante conturbado que, além das injunções próprias do período, convivia com o processo eleitoral para a escolha do mandatário municipal, ou seja, o poder político estava em jogo. 
Em 1961, as eleições provocaram mudança no quadro sucessório e de dirigente político. A desvinculação do voto permitia que, além do prefeito, fosse escolhido o vice-prefeito, independentemente de filiação partidária.

O PSD indicou Moura Carvalho e Isaac Soares. Os demais postulantes eram Alice Antunes e José Ubiratan do Rosário, Stélio Maroja e Jacynto Rodrigues e Marvalho Narciso Belo (sem candidato a vice). Os vencedores foram Moura Carvalho e Isaac Soares, constituindo-se na primeira vitória do PSD, em Belém (cf. ROCQUE, 2001).

Nesse processo eleitoral o $\mathrm{PCB}$, apoiou o candidato vitorioso, logo, há de inferir que no plano institucional formal a possibilidade do partido influenciar nas tomadas de decisões políticas estavam potencialmente colocadas.

Em relação ao ensino, no que tange ao órgão oficial de ensino, Departamento de Educação e Cultura, assinala a sua importância para Belém do Pará, mas deixa claro que a organização do órgão encontrava-se comprometida com irregularidades, afetando, desse modo, o ensino de modo geral.

Organização do Departamento. Encontramos este importante setor da vida do Município eivado de irregularidades, bastando que se saliente desde logo a irregularidade do encerramento do ano letivo, que obrigou ao retorno de atividades escolares professores e alunos para aplicação de novas provas onde se pudesse aferir a capacidade intelectual dos educandos (PREFEITURA MUNICIPAL DE BELÉM, 1962, p. 18. Grifo nosso).

Em relação às escolas, apresenta uma situação que alimenta a idéia do “caos social” por que passava o departamento responsável pela coordenação do ensino sob a responsabilidade do poder público.

Presentemente possui o Município de Belém 40 escolas, devidamente criadas por lei, tendo funcionado no ano passado somente 24. Precário era o estado das escolas municipais, todas desprovidas de material e sem carteiras, exigindo imediata atenção da atual administração (PREFEITURA MUNICIPAL DE BELÉM, 1962, p. 18).

Ao detalhar as demais atribuições do Departamento de Educação e Cultura, enfatiza que entre elas estão as coordenações das divisões de Extra-Escolar, Merenda Escolar, Assistência Social e Biblioteca Municipal. Em relação a essa última divisão, o objetivo seria promover o hábito da leitura bem orientada para que benefícios intelectuais pudessem ser colhidos entre os estudantes belenenses, por isso a necessidade de reordenamente de tal serviço. Para tanto, foram articulados "entendimentos com a Superintendência de Valorização da Amazônia serão promovidos no sentido de conseguir pequenas bibliotecas, que serão doadas aos diversos estabelecimentos de ensino municipal" (PMB, 1962, p. 20). Sublinha-se que a criação de pequenas bibliotecas era uma das reivindicações do PCB, na década de 1940.

Nesse contexto, o panorama político-social contava com a participação do PCB, que lutava para que o Estado do Pará, particularmente Belém, se tornasse democrático de fato e de direito, empunhava bandeira como os educacionais como a criação de grupos escolares noturnos para adultos e criação de pequenas bibliotecas para 
a garantia da educação como um direito de todos. A luta pela garantia da educação como direito é indelével na fala de Oliveira (2006) ${ }^{13}$.

Eu reafirmo isso: o Partido Comunista teve um papel importante na afirmação do direito à educação. Não tenho nenhuma dúvida com relação a isso, claro, que hoje são outros tempos, estou falando na Gênese da tese como ela começou e como ela se desenvolveu, num determinado período. Eu acho que essa questão de estabelecer a educação como um direito de cidadania, assim como também a saúde, toda pessoa tem direito à saúde, passa a ser um dever do Estado um direito do cidadão quer dizer, esse direito de cidadania relacionado com a educação, com a saúde não há nenhuma dúvida de que a grande história, o grande papel político lançado por um partido aqui, foi o Partido Comunista, até porque, só os comunistas podiam fazer isso.

\section{Considerações finais}

A discussão engendrada, no decorrer do texto tendo por base a análise de fontes documentais e depoimentos de comunistas históricos, possibilita afirmar que o PCB não mediu esforços para que o poder político instituído cumprisse com seu dever constitucional de oferta do ensino e que parte das demandas sociais educacionais asseguradas institucionalmente, foi articulada pelos movimentos sociais organizados sob a liderança do partido; que os prefeitos se esforçaram para demonstrar empenho na aplicação das leis aprovadas que criavam novas escolas e permitiam a expansão dos estabelecimentos de ensino, visando à garantia do atendimento ao ensino público primário municipal, bem como dos órgãos responsáveis pela sua coordenação. Desse modo é possível afirmar que o PCB, de 1945-1 o PCB, de 1945-1964, de fato, exerceu um papel importante na história da construção do ensino público primário de Belém do Pará. A movimentação se deu a partir de orientações nacionais e da produção articulada, discutida e elaborada pelos comunistas paraenses, que se configurou em um projeto de educação. Tal projeto foi discutido com a sociedade belenense e serviu de base a criação de escolas e órgãos oficiais de ensino municipal - Diretoria de Ensino, em 1949 e o Departamento de Ensino Municipal, em 1958.

\section{Referências Bibliográficas}

BOBBIO, Norberto. Liberalismo e democracia. Tradução de Marco Aurélio Nogueira. São Paulo: Brasiliense, 1998.

ESTADO DO PARÁ. Mensagemapresentada à Assembléia Legislativa, em sua reunião ordinária, de 1954, pelo General de divisão Zacarias de Assunção, governador do Estado. Belém - PA: Imprensa Oficial, 1954.

PREFEITURA MUNICIPAL DE BELÉM. Mensagem apresentada à Câmara Municipal de Belém, em 1950: Belém-PA, Imprensa Oficial, 1950.

PREFEITURA MUNICIPAL DE BELÉM. Mensagem apresentada à Câmara Municipal de Belém, em 1953: Belém - PA, Imprensa Oficial, 1953. 
PREFEITURA MUNICIPAL DE BELÉM. Mensagem apresentada à Câmara Municipal de Belém, em 1957: Belém - PA, mimeo (50 p.), 1957.

PREFEITURA MUNICIPAL DE BELÉM. Mensagem, apresentada à Câmara Municipal de Belém, em 1958: Belém - PA, Imprensa Oficial, 1958.

PREFEITURA MUNICIPAL DE BELÉM. Mensagem apresentada à Câmara Municipal de Belém, em 1959: Belém - PA, Gráfica Falangola, Editora, 1959.

PREFEITURA MUNICIPAL DE BELÉM. Mensagem apresentada à Câmara Municipal de Belém, em 1960: Belém - PA, Gráfica Falangola Editora, 1960.

PREFEITURA MUNICIPAL DE BELÉM. Mensagem apresentada à Câmara Municipal de Belém, em 1961: Belém - PA, Imprensa Oficial, 1961.

PREFEITURA MUNICIPAL DE BELÉM. Mensagem, apresentada à Câmara Municipal de Belém, em 1962: Belém-PA, Gráfica FaIangola Editora, 1962.

Notas

${ }^{1} \mathrm{O}$ texto é parte da tese de doutorado intitulada, "O PCB e a organização do ensino público debelem do Pará, de 1945 a 1964", defendida em 2006, no PPGE-UFSCAR e foi apresentado na X Jornada do HISTEDBR, realizada em Vitória da Conquista-BA, em $2011 .$.

${ }^{2}$ Entrevista por Alfredo Oliveira, em 19 de setembro de 2006.

${ }^{3}$ Entrevista concedida por Alfredo Oliveira, em 19 de setembro de 2006.

${ }^{4}$ Rui Barata, poeta, professor e militante do PCB. Essa fala encontra-se em: Oliveira (1990, p. 30).

${ }^{5}$ Entrevista concedida por Alfredo Oliveira em 19 de setembro de 2006.

${ }^{6}$ Entrevista concedida por Alfredo Oliveira em 19 de setembro de 2006.

${ }^{7}$ A disciplina Educação Moral e Cívica foi incluída, inicialmente no currículo, durante o Estado Novo.

${ }^{8}$ Entrevista concedida por José Mariano Klautau de Araújo, em 17 de Setembro de 2006.

${ }^{9}$ Entrevista concedida por Carlos de Sá Pereira, em 21 de julho de 2006.

${ }^{10}$ Entrevista concedida por Alfredo Oliveira em 19 de setembro de 2006.

${ }^{11}$ Entrevista concedida por Alfredo Oliveira em 19 de setembro de 2006.

${ }^{12}$ Última Mensagem do período de 1945 a 1964.

${ }^{13}$ Entrevista concedida por Alfredo Oliveira, em 19 de setembro de 2006.

Recebido em: $\quad$ 19/07/2011

Aprovado em: $\quad 25 / 07 / 2011$ 